\title{
SUBLINGUAL DRUG DELIVERY: AN INDICATION OF POTENTIAL ALTERNATIVE ROUTE
}

\author{
PUJA SAHA ${ }^{*}$, SUSHMA VERMA², PRATIK SWARUP DAS ${ }^{1}$
}

${ }^{1}$ Noida Institute of Engineering and Technology, ${ }^{2}$ Pharmacy Institute, Noida Institute of Engineering and Technology

Email: pujasahaps070@gmail.com

Received: 20 Aug 2017, Revised and Accepted: 13 Oct 2017

\begin{abstract}
Sublingual literally meaning is "under the tongue", refers to a method of administrating substance via mouth in such a way that the substance is rapidly absorbed via blood vessels under tongue. Sublingual route is useful when a rapid onset of action is desired with better patient compliance than orally ingested tablets. Drugs that are given sublingually reach directly into the systemic circulation through the ventral surface of the tongue and floor of the mouth. The portion of drug absorbed through the sublingual blood vessels bypasses the hepatic first-pass metabolic processes giving acceptable bioavailability. As nowadays most of the people need effective relief within a short period of time so sublingual is the most suitable form of administration. New sublingual technologies address many pharmaceutical and patient needs, ranging from enhanced life-cycle management to convenient dosing for paediatric, geriatric, and psychiatric patients with dysphagia.
\end{abstract}

Keywords: Sublingual route, Patient compliance, Dysphagia, Sublingual technologies

(C) 2017 The Authors. Published by Innovare Academic Sciences Pvt Ltd. This is an open access article under the CC BY license (http://creativecommons.org/licenses/by/4.0/) DOI: http://dx.doi.org/10.22159/ijcpr.2017v9i6.23436

\section{INTRODUCTION}

Sublingual administration of the drug means placement of the drug under the tongue and the drug reaches directly into the bloodstream through the ventral surface of the tongue and floor of the mouth. The drug solutes are rapidly absorbed into the reticulated vein which lies underneath the oral mucosa, and transported through the facial veins, internal jugular vein, and brachiocephalic vein and then drained into systemic circulation. The routes of absorption via the highly vascularized buccal mucosa allow the substance a more direct access to the blood circulation, thus providing direct systemic administration [1].

Medically, sublingual drug administration is applied in the field of cardiovascular drugs, steroids, some barbiturates and enzymes. It has been a developing field in the administration of many vitamins and minerals which are found to be readily and thoroughly absorbed by this method [2].

\section{Mechanism of sublingual absorption}

The mucosal lining consists of three distinct layers. The outermost layer is the epithelial membrane, which consists of stratified squamous epithelial cells and has a protective barrier function. The innermost layer of the epithelial membrane is called the basement membrane that replenishes the epithelium. Below the epithelium lies the lamina propria followed by the submucosa. The lamina propria is a hydrated and less dense layer of connective tissue containing collagen and elastic fibres [3]. The oral submucosa is also richly supplied with blood vessels [4].

The following absorption through the mucous membrane in the sublingual region, the drug instantly diffuses into venous blood. The venous blood from the sublingual region of the oral cavity drains into a common trunk, which then drains via the internal jugular vein, the subclavian vein, and the brachiocephalic vein directly into the superior vena cava. 8Thus, venous return from these regions enter the systemic circulation, bypassing the pre-systemic drug elimination, unlike in oral administration. Direct drainage into systemic circulation results in the immediate systemic availability of the drug and rapid onset of action. It should be noted that smoking, which causes vasoconstriction, may affect drug absorption [5].

\section{Drugs for sublingual administration}

Sublingually absorbed nutrition, which avoids exposure to the gastric system and liver, means direct nutritional benefits, particularly important for sufferers of gastrointestinal difficulties such as ulcers, hyperactive gut, coeliac disease, those with compromised digestion, the elderly and invalids-the nutritional benefit is independent of gastro-intestinal influences 10.

Examples of drugs administered by this route include antianginal like nitrites and nitrates, antihypertensive like nifedipine, analgesics like morphine and bronchodilators like fenoterol. Certain steroids like estradiol and peptides like oxytocin can also be administered e. g. fentanyl citrate, apomorphine, prochlorperazine dimaleate $\{P R O\}$, and hydrazine $\mathrm{HCl}\{\mathrm{HYD}\}[6]$.

\section{Factors affecting the sublingual absorption [7]}

> Thickness of oral epithelium: As the thickness of sublingual epithelium is $100-200 \mu \mathrm{m}$ which is less as compared to buccal thickness. So the absorption of drugs is faster due to the thinner epithelium and also the immersion of drug in smaller volume of saliva.

$>$ Lipophilicity of drug: For a drug to be absorbed completely through sublingual route, the drug must have slightly higher lipid solubility than that required for GI absorption is necessary for passive permeation.

$>$ pH and pKa of the saliva: As the mean $\mathrm{pH}$ of the saliva is 6.0, this $\mathrm{pH}$ favors the absorption of drugs which remain unionized. Also, the absorption of the drugs through the oral mucosa occurs if the $\mathrm{pKa}$ is greater than 2 for an acid and less than 10 for a base.

$>$ Oil to water partition coefficient: Compounds with favorable oil to- water partition coefficients are readily absorbed through the oral mucosa. An oil-water partition coefficient range of 40-2000 is considered optimal for the drugs to be absorbed sublingually.

$>$ Solubility in salivary secretion: In addition to high lipid solubility, the drug should be soluble in aqueous buccal fluids i.e. biphasic solubility of the drug is necessary for absorption.

$>$ Binding to oral mucosa: Systemic availability of drugs that bind to oral mucosa is poor.

\section{Advantages [8]}

- Liver is bypassed and also drug is protected from degradation due to $\mathrm{pH}$ and digestive enzymes of the middle gastrointestinal tract.

- Improved patient compliance due to the elimination of associated pain with injections; administration of drugs in unconscious or 
incapacitated patients; convenience of administration as compared to injections or oral medications.

- Low dosage gives high efficacy as hepatic first-pass metabolism is avoided and also reduces the risk of side effects.

- Due to rapidity in action, these sublingual dosage forms are widely used in emergency conditions e. g. asthma.

- The large contact surface of the oral cavity contributes to rapid and extensive drug absorption.

- A relatively rapid onset of action can be achieved compared to the oral route, and the formulation can be removed if therapy is required to be discontinued.

- Rapid absorption and higher blood levels due to high vascularization of the region and therefore particularly useful for administration of antianginal drugs.

- They also present the advantage of providing fast dissolution or disintegration in the oral cavity, without the need for water or chewing.

\section{Disadvantages [9]}

- Sublingual medication cannot be used when a patient is uncooperative.

- Since sublingual administration of drugs interferes with eating, drinking, and talking, this route is generally considered unsuitable for prolonged administration.

- The patient should not smoke while taking sublingual medication because smoking causes vasoconstriction of the vessels. This will decrease the absorption of the medication.

\section{Formulation aspects of sublingual tablet}

The distinct feature in the formulation of sublingual tablets involves the selection of suitable excipients of bland taste that shall ultimately resulting in a rapidly disintegrating tablet their by enhancing the dissolution of active ingredient [10].

There are two different types of the sublingual tablet:

\section{Molded Sublingual Tablets.}

2. Compressed Sublingual Tablets.

\section{Molded sublingual tablets}

Molded sublingual tablets are usually prepared from soluble ingredients so that the tablets are completely and rapidly soluble. They contain, in addition to the drug, an excipient or base namely lactose, dextrose, sucrose, mannitol or other rapidly soluble materials or mixtures of these ingredients. Tablets containing insoluble excipients may be prepared from finally divided kaolin, calcium carbonate, calcium phosphate or other insoluble powders. To insure rapid solubility of the soluble tablets, the excipients are usually passed through a fine screen or \# 120 mesh bolting cloth. After the excipients are blended with the drug, the powder mix is moistened with the solvent, which is most commonly alcohol and water mixture. Other volatile solvents, such as acetone or hydrocarbons, may also be used. Antioxidants such as sodium bisulphate and buffers or other ingredients may be added to improve the physical and chemical stability of the product. To increase the hardness and reduce the erosion on the edges of the tablets during handling, agents such as glucose, sucrose, acacia or povidone may be added to the solvent mixture [11-12].

\section{Compressed sublingual tablets}

Compressed sublingual tablets can be prepared by two different methods:

\section{a) Wet Granulation method}

b) Direct compression method

The directly compressible sublingual tablet formulation contains directly compressible soluble excipients, a super disintegrant, and lubricant. It may also contain microcrystalline cellulose, a dry binder, buffers, surface-active agents, sweeteners, and flavors. Sugar-based excipients are widely used as bulking agents because of their high aqueous solubility, sweetness, pleasant feeling in the mouth, and good tastemasking. Nearly all sublingual formulations incorporate some saccharide-based material. The choice of a suitable disintegrant and its amount are critical for achieving a fast disintegration and dissolution rate. Sometimes effervescent agents are used to increasing disintegration and dissolution of sublingual tablets [13].

Several novel approaches of incorporating disintegrants and other soluble and/or insoluble excipients to obtain rapid dissolution and adequate mechanical strength are reported. One example is the Flash tab technology of multiparticulate actives (coated crystals and uncoated or coated microgranules) [14-15]. In these tablets, the simultaneous presence of a disintegrant with a high swelling or disintegrating force, defined as "disintegrating agent," and a substance with a low swelling force (starch, cellulose, and directcompression sugar), defined as "swelling agent," was claimed as the key factor for the rapid disintegration of a tablet. The tablet manufactured by this technology is reported to have adequate mechanical strength [16].

\section{In vitro and in vivo evaluation}

\section{Physical evaluation}

- All batches of sublingual formulations like tablets and films were evaluated for weight variation and drug content. But hardness and friability were calculated for tablets.

- As the hardness of sublingual tablet is an important factor because if the sublingual tablet is too hard, the solvent-borne drug attenuation may not occur into the interior portion of the tablet and therefore remain on a surface portion of the tablet, where the drug attenuation may not adhere to the sublingual tablet [17].

- If the sublingual tablet is too soft, the sublingual tablet may be disintegrated by the solvent of the drug attenuation. Preferably, the solvent-borne drug attenuation should be absorbed into the interior of the sublingual tablet.

- Weight variation test is conducted by selecting 20 tablets at random as per I. P.

- Sublingual films were also evaluated for thickness using micrometre screw gauge [18], tensile strength [19], folding endurance [20], surface $\mathrm{pH}$ [21], and swelling index [22].

\section{Disintegration time (DT)}

A relatively simple method with rigorous conditions has been developed to evaluate the DT of sublingual tablets. Each individual tablet is dropped into $10-\mathrm{mL}$ glass test tube $(1.5-\mathrm{cm}$ diameter containing $2 \mathrm{ml}$ distilled water, and the time required for complete tablet disintegration is observed visually and recorded using a stopwatch. The visual inspection can be enhanced by gently rotating the test tube at a $45^{\circ}$ angle, without agitation, to distribute any tablet particles that might mask any remaining undisintegrated portion of the tablets.

In the USP disintegration test for sublingual tablets, the disintegration apparatus for oral tablets is used without the covering plastic disks, and $2 \mathrm{~min}^{*}$ is specified as the acceptable time limit for tablet disintegration [23].

\section{Wetting time (WT)}

Although a wetting test is not a USP standard test, it is useful for quality control and provides a supportive evaluation of these sublingual tablets. Using this test, the time required for moisture to penetrate the tablet completely is measured and possibly represents the time required to release the drug in the presence of minute volumes of saliva [24].

\section{Friability}

Twenty tablets are to be weighed and placed in a Roche friabilator and the equipment has to be rotated at $25 \mathrm{rpm}$ for $4 \mathrm{~min}$. The tablets 
were taken out, dedusted, and reweighed. The percentage friability of the tablets can be calculated by:

$$
\% \text { Friability }=\frac{\text { Initial Weight }- \text { Final Weight }}{\text { Initial Weight }} \text { X } 100
$$

\section{In vivo evaluation}

\section{Pharmacokinetic data analysis and bioavailability evaluation}

Rabbits have been described as one of the few laboratory animals that do not have keratinized mucosa, thus closely resembling human sublingual mucosal tissue 25. The maximal plasma concentration (Cmax) and the time to reach maximum plasma concentration (Tmax) can be directly obtained from the plasma data. The area under the plasma concentration curve (AUC) can also calculate using the trapezoidal rule and then the bioavailability [25].

\section{Permeation studies}

Ex vivo permeation studies through porcine oral mucosa can be carried out using the modified Franz diffusion cell of the internal diameter of $2.5 \mathrm{~cm}$. The buccal mucosa has to be excised and trimmed evenly from the sides and then washed in isotonic phosphate buffer of pH 6.6 and used immediately. The membrane needs to be stabilized before mounting to remove the soluble components. The mucosa has to be mounted between the donor and receptor compartments. The receptor compartment has to be filled with $200 \mathrm{ml}$ of isotonic phosphate buffer of $\mathrm{pH} 7.4$ which is maintained at $37 \pm 0.2{ }^{\circ} \mathrm{C}$ and hydrodynamics has to be maintained by stirring with a magnetic bead at $50 \mathrm{rpm}$. The donor compartment has to be filled with $1 \mathrm{ml}$ of simulated saliva of $\mathrm{pH}$ 6.8. Samples are to be withdrawn at suitable interval replacing the same amount with fresh medium 26, 27. The percentage of drug permeated can be determined by measuring the absorbance in a UV-Visible spectrophotometer [26-27].

\section{Recent developments}

Nitroglycerine-delivering sublingual aerosol formulation (nitroglycerine in propellants) in a metered-dose spraying pump, Nitrolingual spray, was developed. It delivers nitroglycerine by spraying onto or under the tongue in the form of spray droplets, which ultimately increase the absorption and hence the bioavailability of nitroglycerine. The rapid onset of action is always required in case of hypertension.

\section{CONCLUSION}

In conclusion, this review demonstrates that there are a number of commercially available sublingual formulations manufactured using various technologies. The publically available information on sublingual tablets implies that this dosage form has good potential to enhance drug delivery in treating a number of indications. In most reported cases, it has been shown that the sublingual dosage form not only improves the patient's compliance, but also reduces the time for the onset of the drug action, and increases the bioavailability of drugs as compared to conventional tablets. Therefore sublingual tablets are an accepted technology for systemic delivery of drugs.

\section{CONFLICT OF INTERESTS}

Declared none

\section{REFERENCES}

1. Ishikawa $\mathrm{T}$, Koizumi N, Mukai B. Pharmacokinetics of acetaminophen from rapidly disintegrating compressed tablet prepared using microcrystalline cellulose (PH-M-06) and spherical sugar granules. Chem Pharm Bull 2009;49:230-2.

2. Price TM, Blauer KL, Hansen M, Stanczyk F, Lobo R, Bates GW. Single-dose pharmacokinetics of sublingual versus oral administration of micronized 17 beta-estradiol. Obstet Gynecol 2007;89:340-5.

3. KL Moore, AF Dalley, Anne MR. Agur. Eds. Clinically Oriented Anatomy. 6th ed. Lippincott Williams and Wilkins, Philadelphia, PA; 2009. p. 944.
4. CA Squier, PW Wertz. Structure and function of the oral mucosa and implications for drug delivery," in oral mucosal drug delivery. MJ Tathbone. Ed. (Marcel Dekker, New York, NY; 2006. p. 1-26.

5. Kurosaki Y, Takatori T, Nishimura H, Nakayama T, Kimura T. Regional variation in oral mucosal drug absorption permeability and degree of keratinization in hamster oral cavity. Pharm Res 2011;8:1297-301.

6. Narang N, Sharma J. Sublingual mucosa as a route for systemic drug delivery. Int J Pharm Pharm Sci 2010;3:18-22.

7. Richman MD, Fox D, Shangraw RF. Preparation and stability of glyceryl trinitrate sublingual tablets prepared by direct compression. J Pharm Sci 2015;54:447-51.

8. Fu Y, Yang S, Jeong SH, Kimura S, Park K. Orally fast disintegrating tablets: developments, technologies, tastemaking and clinical studies. Crit Rev Ther Drug Carrier Syst 2014;21:433-76.

9. Katz M, Barr M. A study of sublingual absorption I. Several factors influencing the rate of adsorption. J Am Pharm Assoc Am Pharm Assoc (Baltim) 2015;44:419-23.

10. Koland M, Sandeep VP, Charyulu NR. Fast dissolving sublingual films of ondansetron hydrochloride: effect of additives on in vitro drug release and mucosal permeation. J Young Pharm 2010;2:216-2.

11. Fung HL, Yap SK, Rhodes CT. Development of a stable sublingual nitroglycerine tablets. Formulation and evaluation of tablet containing povidone. J Pharm Sci 2006;65:558-60.

12. Nandita GD, Sudip KD. Development of mucoadhesive dosage forms of buprenorphine for sublingual drug delivery. Drug Delivery 2004;11:89-95.

13. Sindhu Abraham, Basavaraj BV, Bharath S, Deveswaran R, Sharon F, Madhavan V. Formulation and optimization of sublingual tablets of rabeprazole sodium. Int J Pharm Sci Res 2010;5:50-4.

14. Boer D. Drug absorption by sublingual and rectal routes. Br J Anaesthesia 2014;56:69-82.

15. Al-Ghananeem AM, Malkawi AH, Crooks PA. Effect of $\mathrm{pH}$ on the sublingual absorption of oxycodone hydrochloride. AAPS PharmSciTech 2016;7:23.

16. John DN, Fort S, Lewis MJ, Luscombe DK. Pharmacokinetics and pharmacodynamics of Verapamil following sublingual and oral administration to healthy volunteers. $\mathrm{Br} \mathrm{J}$ Clin Pham 2012;33:623-7.

17. Rameshwari S, Jeya AJ. Formulation and evaluation of nifedipine sublingual tablets. Asian J Pharm Clin Res 2009;2:44-8.

18. Nafee NA, Boraie NA, Ismail FA, Mortada IM. Design and characterization of mucoadhesive buccal patches containing cetylpyridinium chloride. Acta Pharm 2013;53:199-212.

19. Bottenbrg P, Cleymact R, dc Muynck C, Reymon JP, Coomans D, Michotte $\mathrm{Y}$, et al. Development and testing of fluoridecontaining slow release tablets for oral use. J Pharm Pharmacol 2001;43:457-64.

20. Peh KK, Wong CF. Polymeric films as vehicles for buccal delivery; swelling, mechanical, and bioadhesive properties. J Pharm Sci 2009;2:53-61.

21. Yeola GS, Darandale S, Khire A, Vavia PR. Fabrication and statistical optimization of a polysaccharide-based sublingual film of buprenorphine hydrochloride for breakthrough pain management: in vitro and in vivo performance. Drug Delivery Translational Res 2014;4:116-25.

22. Sudarshan K Singh, Agham A Sameer. Development and characterization of a sublingual tablet of Lisinopril. Asian Pacific J Trop Biomed 2012;11:236-369.

23. Haegeli L, Brunner-La Rocca HP, Wenk M, Pfisterer M, Drewe J, Krahenbuhl S. Sublingual administration of furosemide: a new application of an old drug. Br J Clin Pharmcol 2007;64:804-9.

24. USP/NF. Physical tests: disintegration 22/17. ed. Rockville MD: United States Pharmacopoeial Convention Inc; 1990.

25. USP/NF. Official Monographs: Nitroglycerin Tablets. 22/17. ed. Rockville MD: United States Pharmacopoeial Convention Inc; 1990.

26. Patel MV, Prajapati BG, Patel MM. Effect of hydrophilic polymers on buccoadhesive Eudragit patches of propranolol hydrochloride using factorial design. AAPS PharmSciTech 2007;8:45.

27. Semalty M, Semalty A, Kumar G. Formulation and characterization of mucoadhesive buccal films of glipizide. Indian J Pharm Sci 2008;70:43-8. 